\title{
O INTERESSE PÚBLICO NA TEORIA DISCURSIVA DO DIREITO
}

\author{
Christiane Costa Assis*
}

SUMÁRIO: 1. Introdução. 2. Desconstrução do protagonismo estatal na persecução do interesse público. 3. O papel do debate na formação do interesse público. 4. Conclusão. 5. Referências.

RESUMO: O presente trabalho tem como objetivo principal analisar a evolução do conceito de interesse público no Direito Administrativo decorrente das mudanças de paradigmas estatais, bem como na hermenêutica jurídica. A passagem de uma hermenêutica jurídica fechada para uma sociedade aberta de intérpretes provocou alterações na delimitação do interesse público e do interesse privado. Na nova hermenêutica, o discurso passou a ser o elemento delimitador dos interesses, sendo ainda o mecanismo de atuação da sociedade na construção do Direito Administrativo no contexto da democracia participativa. A presente pesquisa se propõe analisar a mencionada evolução do interesse público, bem como as contribuições da Teoria Discursiva do Direito para a busca do mencionado interesse, apresentando breve exposição de algumas obras relevantes sobre o tema. Como resultado, espera-se demonstrar a compatibilidade do interesse público pela ótica da Teoria Discursiva do Direito de Jürgen Habermas com o Direito Administrativo do Estado contemporâneo.

Palavras-chave: Hermenêutica. Interpretação jurídica. Direito Administrativo.

\begin{abstract}
The goal of this paper is to analyze the evolution of the concept of public interest in administrative law that resulted from the changes of states paradigm, and also legal hermeneutics. The passage of a closed legal hermeneutic to an open society of interpreters led to changes in the definition of public interest and private interest. In the new hermeneutic, the discourse became the main delimiter of interest, and also the mechanism of action of society in the construction of administrative law in the context of participatory democracy. This study aims to analyze the developments of public interest mentioned above, as well as the contributions of Discourse Theory of Law for the search of that interest, with brief exposure of some relevant works on the subject. As a result, it is expected to demonstrate the compatibility of public interest from the perspective of the Discourse Theory of Law of Jürgen Habermas with Administrative Law of the contemporary state.
\end{abstract}

Keywords: Hermeneutic. Legal interpretation. Administrative Law.

\section{INTRODUÇÃO}

O interesse público dentro do Direito Administrativo tem papel norteador para a atuação da Administração Pública. Ainda que a atuação ocorra em atendimento a um interesse estatal imediato, o interesse público também deve ser atendido sob pena de nulidade devido à ocorrência do desvio de finalidade (CARVALHO FILHO, 2009: p. 30). A noção de interesse público teve início após a Revolução Francesa, na qual os revolucionários afirmavam que suas ações eram pautadas pelo bem comum, o que propiciava uma maior aceitação pela sociedade e justificava o poder do Estado, principalmente em situações de restrições impostas aos direitos dos particulares (MEDAUAR, 1992: p. 189). Dessa forma, ocorreu a separação entre a esfera pública e privada, sendo que "ao

\footnotetext{
* Bacharela em Direito pela Pontifícia Universidade Católica de Minas Gerais - PUC/MG; Especializanda em Direito Público pela PUC/MG. Advogada.
} 
Poder Público cabia o zelo pelo interesse público; ao particular, o âmbito privado, e, pois, o que se referia ao interesse privado" (MEDAUAR, 1992: p. 189). Nesse contexto do século XIX, a Administração executava a lei (fruto da vontade geral), consistindo na única intérprete do interesse público, o que conseqüentemente possibilitava a "homogenização dos interesses", como explica Odete Medauar:

A Administração realiza, assim, uma espécie de homogenização dos interesses, o que pressupões uma concepção de sociedade homogênea, com redução de todos os interesses a um denominador comum. Raciocinava-se, desse modo, em torno de interesse público e interesse individual, de regra, em contraposição, para afirmar-se, na atividade administrativa, a primazia do primeiro em relação ao segundo. (MEDAUAR, 1992: p. 189).

Enquanto no Estado Liberal a esfera pública se mostrava sobreposta à esfera privada, no Estado Social ocorreu verdadeira inversão, privilegiando-se a segunda em detrimento da primeira. Já no Estado Democrático de Direito as duas esferas co-existem, porém sem contornos bem definidos. Mencionada alteração se deve à mudança da interpretação dos conceitos de interesse público e interesse privado, que não mais são vistos como interesses indissociados e fechados em si mesmos, face à atual sociedade pluralista. Dessa forma, a participação popular na construção do interesse público se mostrou necessária, provocando um compartilhamento do Estado com a sociedade na persecução do mesmo.

\section{DESCONSTRUÇÃO DO PROTAGONISMO ESTATAL NA PERSECUÇÃO DO INTERESSE PÚBLICO}

A Administração Pública em uma concepção clássica sempre foi a tutora dos interesses públicos entendidos como interesses gerais concebidos à priori, sem necessidade de participação da sociedade para sua definição. Uma vez configurado o interesse da coletividade, na concepção clássica, trata-se genuinamente de interesse público. Nesse sentido, o Estado seria uma entidade promotora do interesse público entendido como bem estar dos indivíduos, cujo mecanismo de atuação seria o Direito.

A compreensão do Estado como protagonista do interesse público provoca a distinção de duas esferas: a esfera privada, que cuida dos interesses referentes às questões patrimoniais, relações civis, instituições familiares, entre outros; e a esfera pública, que cuida dos interesses da Administração Pública em si e ainda dos interesses coletivos, tais como segurança pública, proteção ambiental e bem estar social (FARIA, 2007: p. 12). Ao Estado caberia a persecução dos interesses públicos, atuando restritamente nos ditames da lei, podendo inclusive limitar os interesses individuais. Referida limitação se fundamenta na supremacia do interesse público sobre o privado que, por sua 
vez, seria uma regra de preferência pelo bem comum aplicada pela Administração Pública.

Luis Roberto Barroso divide o interesse público em primário e secundário, o que segundo o autor prova diferenciações na aplicação da supremacia do interesse público. $\mathrm{O}$ interesse público primário se refere aos interesses da coletividade, enquanto o interesse público secundário se refere ao interesse do erário, posto que consiste no interesse da pessoa jurídica de direito público na situação em questão. Explica o autor:

O interesse público secundário - i. e., o da pessoa jurídica de direito público, o do erário - jamais desfrutará de supremacia a priori e abstrata em face do interesse particular.

[...]

O interesse público primário, consubstanciado em valores fundamentais como justiça e segurança, há de desfrutar de supremacia em um sistema constitucional e democrático Deverá ele pautar todas as relações jurídicas e sociais - dos particulares entre si, deles com as pessoas de direito público e destas entre si. (BARROSO, 2009: p. 70/71).

A evolução do Direito Administrativo demonstrou que uma préconcepção de interesse público não mais satisfaz aos anseios da sociedade pluralista contemporânea, sendo necessário que o particular participe da construção do interesse público, no intuito de conferir legitimidade à atuação da Administração Pública. Trata-se da democracia participativa, na qual os destinatários são também co-autores das normas:

Todo aquele que vive no contexto regulado por uma norma e que vive com este contexto é, indireta ou, até mesmo diretamente, um intérprete dessa norma. O destinatário da norma é participante ativo, muito mais ativo do que se pode supor tradicionalmente, do processo hermenêutico. Como não são apenas os intérpretes jurídicos da Constituição que vivem a norma, não detêm eles o monopólio da interpretação da Constituição (HÄBERLE, 2002: p.15).

Percebe-se, portanto, que a legitimidade do Estado não mais decorre da simples atuação do mesmo em prol da redução das desigualdades, tal qual pregava o Estado Social, que se preocupava com os resultados e não com os fundamentos de sua atuação. Não mais se admite uma atuação exclusiva do Estado na busca pela realização do interesse público, posto que referido interesse somente é passível de determinação através da participação popular.

Como consequiência da participação popular, há dinamicidade no interesse público que se altera conforme a evolução e as novas necessidades da sociedade. O interesse público, portanto, não é um conceito estático e fechado em si, pois deve acompanhar as modificações da vida em comum e estar sempre aberto ao debate. Para tanto, é imprescindível que a sociedade se expresse no 
sentido de apontar à Administração Pública quais os rumos que melhor lhe atendem, abrindo caminhos para a "administração participativa":

\begin{abstract}
A idéia de "administração participativa" surge como uma conseqüência da nova concepção de direitos fundamentais e de cidadania, que rejeita a redução do "cidadão" (no sentido de titular da soberania) a um mero "cliente" (recebedor de serviços públicos), redução essa típica do Estado Social. (BARACHO JUNIOR, 2000: p. 164).
\end{abstract}

Caso se admita o Estado como protagonista exclusivo do interesse público seria necessária a separação dos interesses em exclusivamente privados ou exclusivamente públicos, pois caberia ao Estado tutelar apenas estes. Porém, com a abertura interpretativa dos interesses e das esferas, verifica-se a impossibilidade tal separação e, como conseqüência, criou-se uma dificuldade para aplicação de princípios exclusivos da Administração Pública. Como exemplo, pode-se citar o Princípio da Supremacia do Interesse Público, cujas hipóteses de cabimento não mais são identificadas facilmente.

Se eles - o interesse público e o privado - são conceitualmente inseparáveis, a prevalência de um sobre outro fica prejudicada, bem como a contradição entre ambos. A verificação de que a administração deve orientar-se sob o influxo de interesses públicos não significa, nem poderia significar, que se estabeleça uma relação de prevalência entre os interesses públicos e privados. (ÁVILA, 2007: p.14).

Luis Roberto Barroso também atenta para a situação de indissociabilidade dos interesses:

Em um Estado democrático de direito, não subsiste a dualidade cunhada pelo liberalismo, contraponto Estado e sociedade. O Estado é formado pela sociedade e deve perseguir os valores que ela aponta. Já não há uma linha divisória romântica e irreal separando culpas e virtudes (BARROSO, 2009: p. 69).

Percebe-se, portanto, que no Direito Administrativo contemporâneo o interesse público e o interesse privado não são contrapostos e estão misturados, sendo impossível delimitá-los com precisão.

No tocante às esferas, constatou-se que a existência tanto da esfera pública quanto da esfera privada é requisito da democracia. Somente através do diálogo entre as duas esferas é possível atender de fato ao interesse coletivo. A falha dos paradigmas Liberal e Social consistiu no privilégio de uma das esferas em detrimento da outra (BARACHO JUNIOR, 2000: p. 168), mas o Estado Democrático de Direito busca a interação discursiva das mesmas, conforme as idéias desenvolvidas por Habermas. 
Segundo Habermas, sem os direitos fundamentais que asseguram a autonomia privada dos cidadãos, não haveria o médium para a institucionalização jurídica das condições sob as quais os sujeitos de direito podem fazer uso da autonomia pública ao desempenharem seu papel de cidadãos.

Assim, a autonomia pública e a privada pressupõem-se mutuamente, sem que haja primazia de uma sobre a outra. (OLIVEIRA, 2004: p.182).

Jürgen Habermas compõe a nova hermenêutica jurídica inaugurada por Martin Heidegger e Hans-Georg Gadamer. Se no Iluminismo marcado pela Filosofia da Consciência acreditava-se na hermenêutica como método matemático, absoluto e infalível, a hermenêutica característica da Filosofia da Linguagem provocou uma abertura para a interpretação e para a participação da sociedade através do debate nas decisões do Poder Público. Na proposta da Teoria Discursiva da Habermas, o discurso se apresenta como um mecanismo democrático de elaboração do verdadeiro interesse público.

\section{3 . O PAPEL DO DEBATE NA FORMAÇÃO DO INTERESSE PÚBLICO}

A Teoria Discursiva do Direito desenvolvida por Habermas consiste em alternativa ao pensamento objetivista da filosofia da consciência. Embora a mencionada Teoria possua vários aspectos de grande importância, o presente trabalho não pretende esgotá-la e, portanto, mencionará apenas as idéias mais pertinentes ao tema proposto.

Ao partir da teoria de Habermas, o questionamento inicial consiste na dificuldade de delimitação do verdadeiro interesse público. Para o autor a verdade é algo falível e provisório "que pode ser racionalmente aceito [...] e não algo que deva ser cinicamente conveniente para uma dada comunidade" (CRUZ, 2008: p. 159). Esse dinamismo do conceito de verdade é aplicável ao interesse público, uma vez que a sociedade cosmopolita atual faz com que o interesse público sofra constantes mutações para atender a novas demandas. Como já mencionado, o interesse público não deve mais ser visto como um conceito estático, fechado e pré-concebido, pois deve acompanhar à evolução da sociedade. Porém, é essa mesma sociedade quem deverá indicar ao Poder Público quais as decisões que melhor lhe atendem, pois com o fim da hermenêutica positivista percebeu-se que diante dos conceitos indeterminados (como é o caso do interesse público) somente a participação popular é capaz de apontar as direções adequadas ao Estado e ao Direito.

Na proposta de Habermas a definição do verdadeiro interesse público é possível através do debate, no qual "a argumentação tem a forma de um concurso que visa aos melhores argumentos a favor de ou contra pretensões de validade controversas e serve à busca cooperativa da verdade" (HABERMAS, 2004: p. 250). Mencionado debate deve ser constante, pois é necessária uma abertura permanente para novos argumentos (CRUZ, 2009: p. 163). 
Buscando a eqüiprimordialidade entre o público e o privado, Habermas propõe uma nova concepção de esfera pública, que será o espaço para o diálogo. Explica o autor:

A esfera pública pode ser descrita como uma rede adequada para a comunicação de conteúdos, tomadas de posição e opiniões; nela os fluxos comunicacionais são filtrados e sintetizados a ponto de se condensarem em opiniões públicas enfeixadas em temas específicos. Do mesmo modo que o mundo da vida tomado globalmente, a esfera pública se reproduz através do agir comunicativo, implicando apenas o domínio de uma linguagem natural; ela está em sintonia com a compreensibilidade geral da prática comunicativa cotidiana (HABERMAS, 2003: p. 92).

Para que um indivíduo adquira status de pessoa de direito e participe do debate de forma igualitária aos demais, o autor apresenta cinco categorias de direitos que possibilitam a "socialização horizontal":

(1) Direitos fundamentais que resultam da configuração politicamente autônoma do direito à maior medida possível de iguais liberdades subjetivas de ação;

(2) Direitos fundamentais que resultam da configuração politicamente autônoma do status de um membro numa associação voluntária de parceiros do direito;

(3) Direitos fundamentais que resultam imediatamente da possibilidade de postulação judicial de direitos e da configuração politicamente autônoma da proteção jurídica individual;

(4) Direitos fundamentais à participação, em igualdade de chances, em processos de formação de opinião e da vontade, nos quais os civis exercitam sua autonomia política e através dos quais eles criam direito legítimo;

(5) Direitos fundamentais a condições de vida garantidas social, técnica e ecologicamente, na medida em que isso for necessário para um aproveitamento, em igualdade de chances, dos direitos elencados de (1) até (4). (HABERMAS, 2010: p;159/160).

Habermas amplia a esfera pública e abre espaço para o debate no qual poderão figurar argumentos morais, políticos, religiosos, entre outros, não se admitindo, porém, a subtração unilateral dos direitos de cada participante, o que decorre da aplicação do princípio do discurso (HABERMAS, 2010: p.161). Nesse sentido, o Direito é o medium que operacionaliza o debate e proporciona as garantias necessárias para a realização do mesmo.

Convém ressaltar que Habermas não defende o fim do Estado: 
O Estado é necessário como poder de organização, de sanção e de execução, porque os direitos têm que ser implantados, porque a comunidade de direito necessita de uma jurisdição organizada e de uma força para estabilizar a identidade, e porque a formação da vontade política cria programas que têm que ser implementados. (HABERMAS, 2010: p; 171).

Segundo o autor, a necessidade da existência do Estado está ligada à relação interna do Direito com a Política:

[...] o poder organizado politicamente não se achega ao direito como que a partir de fora, uma vez que é pressuposto por ele: ele mesmo se estabelece em formas do direito.O poder político só pode desenvolver-se através de um código jurídico institucionalizado na forma de direitos fundamentais. (HABERMAS, 2010: p. 171).

Assim sendo, o Estado é responsável por executar as definições da sociedade advindas do debate, porém sua legitimidade não decorre da simples eleição. A legitimidade em Habermas decorre da constante participação popular na tomada de decisões, ou seja, decorre da formação discursiva das decisões que deverão obter aceitação racional por todos os membros da sociedade (HABERMAS, 2010: p. 172). A soberania popular, por sua vez, exige "que a legislação expresse a vontade da totalidade dos cidadãos" (CRUZ, 2004: p. 220).

Aplicando-se as idéias de Habermas ao interesse público, percebe-se que a participação da sociedade em sua formação é condição de legitimidade do mesmo. No entanto, referida participação deve sempre buscar o bem comum e não a satisfação de um interesse particular. Nesse ponto, é pertinente a explicação do autor sobre a diferença entre "agir comunicativo" e "agir estratégico", uma vez que no primeiro busca-se um interesse coletivo e no segundo busca-se um interesse individual:

Falamos então de agir comunicativo quando agentes coordenam seus planos de ação mediante o entendimento mútuo lingüístico, ou seja, quando eles os coordenam de tal modo que lançam mão das forças de ligação ilocucionárias próprias dos atos de fala. No agir estratégico, esse potencial de racionalidade comunicativa permanece inutilizado, mesmo quando as interações são lingüisticamente mediadas. Como aqui os envolvidos coordenam seus planos de ação mediante uma influenciação recíproca, a linguagem não é empregada comunicativamente no sentido já explicado, mas de forma orientada a conseqüências. (HABERMAS, 2004: p.118).

Percebe-se, portanto, que nem todo uso da linguagem é comunicativo e nem toda comunicação lingüística busca o entendimento mútuo de forma válida (HABERMAS, 2004: p. 125). Assim sendo, é imprescindível que o patamar 
mínimo de direitos fundamentais seja atendido, pois evita as desigualdades no debate proporcionando uma real busca pelo verdadeiro interesse público. Mencionado debate deverá ocorrer na esfera pública concebida por Habermas, na qual as decisões acerca do interesse público deverão ser abertas e dinâmicas, no intuito de acompanhar as constantes mudanças da atual sociedade pluralista.

\section{CONCLUSÃO}

A evolução dos paradigmas estatais provocou alterações no Direito Administrativo, sendo exigência do atual Estado Democrático de Direito uma democracia participativa que se aplica também ao Poder Executivo. No paradigma atual, percebeu-se que o Estado não é o protagonista exclusivo do interesse público, posto que referido interesse se encontra em constante reformulação para atender aos anseios da sociedade pluralista contemporânea. Para a busca do interesse público a Teoria Discursa do Direito desenvolvida por Jürgen Habermas se apresenta como uma alternativa democrática que possibilita ampla participação da sociedade na esfera pública, rompendo com a concepção de um interesse público pré-concebido e tutelado apenas pelo Estado. A Teoria Discursiva de Habermas propõe ainda a eqüiprimordialidade entre as esferas públicas e privadas, sem que uma esfera se sobreponha à outra. Dessa forma, mencionada teoria se apresenta adequada aos preceitos democráticos, uma vez que é capaz de proporcionar o debate na busca pelo verdadeiro interesse público.

\section{REFERÊNCIAS}

ÁVILA, Humberto. Repensando o "Princípio da Supremacia do Interesse Público sobre o Particular". Revista Eletrônica sobre a Reforma do Estado (RERE). Salvados, Instituto Brasileiro de Direito Público, $\mathrm{n}^{\circ} 11$, setembro/outubro/novembro, 2007. Disponível em: $<$ http://www.direitodoestado.com/revista/RERE-11-SETEMBRO-2007HUMBERTO\%20AVILA.pdf> Acessado em: 22 de maio de 2011.

BARACHO JUNIOR, José Alfredo de Oliveira. Responsabilidade civil por dano ao meio ambiente. Belo Horizonte: Del Rey, 2000.

BARROSO, Luís Roberto. Curso de direito constitucional contemporâneo: os conceitos fundamentais e a construção do novo modelo. São Paulo: Saraiva, 2009.

CARVALHO FILHO, José dos Santos. Manual de direito administrativo. 21. ed. rev., ampl. e atual. Rio de Janeiro: Lumen Juris, 2009.

CRUZ, Álvaro Ricardo de Souza. Habermas e o Direito Brasileiro. 2. ed. Rio de Janeiro: Lúmen Júris, 2008.

CRUZ, Álvaro Ricardo de Souza. Jurisdição constitucional democrática. Belo Horizonte: Del Rey, 2004. 
FARIA, Edimur Ferreira de. Curso de direito administrativo positivo. 6 . ed. ver. e ampl. Belo Horizonte: Del Rey, 2007.

HÄBERLE, Peter. Hermenêutica constitucional. A sociedade aberta dos intérpretes da constituição: contribuição para a interpretação pluralista e "procedimental" da constituição. Tradução de Gilmar Ferreira Mendes. Porto Alegre: Sérgio Antonio Fabris Editor, 2002.

HABERMAS, Jürgen. Direito e democracia: entre a facticidade e validade. Vol. I. 2. ed. Tradução de Flávio Beno Siebeneichler. Rio de Janeiro: Tempo Brasileiro, 2010.

. Direito e democracia: entre a facticidade e validade. Vol. II. 2. ed. Tradução de Flávio Beno Siebeneichler. Rio de Janeiro: Tempo Brasileiro, 2003.

. Verdade e justificação. São Paulo: Loyola, 2004.

MEDAUAR, Odete. O direito administrativo em evolução. 2. ed. São Paulo: Editora Revista dos Tribunais, 1992.

OLIVEIRA, Marcelo Andrade Cattoni de. Jurisdição e hermenêutica constitucional: no Estado democrático de direito. Belo Horizonte:

Mandamentos, 2004.

Recebido em 10-09-2011

Avaliado em 14-11-2011-

Aprovado para publicação em 05-12-2011 